\title{
Estudo de adsorção do corante Nylosan azul N-BLN têxtil em resíduos de semente de
}

\section{maracujá}

\author{
Adsorption study of Nylosan blue N-BLN textile dye on passion fruit residues \\ Estudio de adsorción de colorante textil Nylosan blue N-BLN en residuos de maracuyá
}

Recebido: 09/10/2021 | Revisado: 16/10/2021 | Aceito: 20/10/2021 | Publicado: 22/10/2021

\author{
Matheus Campos Castro \\ ORCID: https://orcid.org/0000-0002-9918-1491 \\ Universidade Estadual de Maringá, Brasil \\ E-mail: 1996mcastro@gmail.com \\ Eloize Silva Alves \\ ORCID: https://orcid.org/0000-0002-3340-8374 \\ Universidade Estadual de Maringá, Brasil \\ E-mail: eloizeetaus@gmail.com \\ Bruno Henrique Figueiredo Saqueti \\ ORCID: https://orcid.org/0000-0002-1118-4605 \\ Universidade Estadual de Maringá, Brasil \\ E-mail: bruno_saqueti@outlook.com \\ Silvana Fernandes Montanher \\ ORCID: https://orcid.org/0000-0002-9421-8507 \\ Universidade Tecnológica Federal do Paraná, Brasil \\ E-mail: silvanafm@utfpr.edu.br
}

\begin{abstract}
Resumo
A indústria têxtil tem-se desenvolvido e crescido cada vez mais, com isso vem usando mais corantes, logo é gerado um volume grande de efluentes altamente coloridos e contaminados, esses efluentes se forem descartados sem um tratamento prévio em corpos hídricos, podem gerar problemas ambientais graves. Uma maneira simples, eficiente e barata de realizar a remoção desses corantes é utilizando a técnica de adsorção. Com isso o presente trabalho pretende demonstrar se resíduos de maracujá, as sementes, que tem baixo valor agregado podem ser utilizado como adsorventes alternativos para o tratamento de efluentes têxtil. Logo o objetivo do trabalho foi avaliar as sementes de maracujá como adsorvente alternativo do corante têxtil Nylosan azul N-BLN, além de avaliar o efeito da força iônica e do $\mathrm{pH}$ da solução na eficiência de adsorção e realizar o avaliar a viabilidade do processo de dessorção. Os estudos de adsorção foram conduzidos em coluna de leito fixo usando os resíduos de maracujá in natura e submetidos a tratamentos químicos com $\mathrm{HCl}$. O tratamento ácido aumentou a eficiência de adsorção da biomassa. A força iônica teve pouca influência sob o processo de adsorção. $\mathrm{O}$ pH influenciou o processo de adsorção, sendo que o melhor valor de $\mathrm{pH}$ foi igual a dois. O processo de dessorção foi possível de acontecer, utilizando como solução extratora hidróxido de sódio $\mathrm{NaOH}$. A capacidade adsortiva para as sementes foi de 10,2 e $20,2 \mathrm{mg} \mathrm{g}^{-1}$ para a biomassas in natura e tratada com $\mathrm{HCl}$.
\end{abstract}

Palavras-chave: Adsorção; Adsorvente alternativo; Nylosan azul N-BLN; Corantes.

\begin{abstract}
The textile industry has developed and grown more and more, with this it has been using more dyes, so a large volume of highly colored and contaminated effluents is generated, these effluents, if discarded without prior treatment in water bodies, can generate environmental problems bass. A simple, efficient and cheap way to carry out the removal of these dyes is using the adsorption technique. With that, the present work intends to demonstrate if passion fruit residues, the seeds, which have low added value, can be used as alternative adsorbents for the treatment of textile effluents. Therefore, the objective of this work was to evaluate the passion fruit seeds as an alternative adsorbent for the Nylosan blue N-BLN textile dye, in addition to evaluating the effect of the ionic strength and $\mathrm{pH}$ of the solution on the adsorption efficiency and to evaluate the viability of the desorption process. The adsorption studies were carried out in a fixed bed column using in natura passion fruit residues and subjected to chemical treatments with $\mathrm{HCl}$. The acid treatment increased the biomass adsorption efficiency. The ionic strength had little influence on the adsorption process. The $\mathrm{pH}$ influenced the adsorption process, and the best $\mathrm{pH}$ value was equal to two. The desorption process was possible to happen, using sodium hydroxide $\mathrm{NaOH}$ as an extracting solution. The adsorptive capacity for seeds was 10.2 and $20.2 \mathrm{mg} \mathrm{g}^{-1}$ for biomass in natura and treated with $\mathrm{HCl}$.
\end{abstract}

Keywords: Adsorption; Alternative adsorbent; Nylosan blue N-BLN; Dyes. 


\begin{abstract}
Resumen
La industria textil se ha desarrollado y crecido cada vez más, con esto se ha venido utilizando más tintes, por lo que se genera un gran volumen de efluentes altamente coloreados y contaminados, estos efluentes, si se descartan sin tratamiento previo en cuerpos de agua, pueden generar problemas ambientales bajos. Una forma sencilla, eficaz y económica de eliminar estos tintes es mediante la técnica de adsorción. Con ello, el presente trabajo pretende demostrar si los residuos de maracuyá, las semillas, que tienen un bajo valor agregado, pueden utilizarse como adsorbentes alternativos para el tratamiento de efluentes textiles. Por lo tanto, el objetivo de este trabajo fue evaluar las semillas de maracuyá como adsorbente alternativo para el tinte textil Nylosan blue N-BLN, además de evaluar el efecto de la fuerza iónica y el pH de la solución sobre la eficiencia de adsorción y evaluar la viabilidad del proceso de desorción. Los estudios de adsorción se realizaron en columna de lecho fijo utilizando residuos de maracuyá in natura y sometidos a tratamientos químicos con $\mathrm{HCl}$. El tratamiento con ácido aumentó la eficiencia de adsorción de biomasa. La fuerza iónica tuvo poca influencia en el proceso de adsorción. El pH influyó en el proceso de adsorción y el mejor valor de $\mathrm{pH}$ fue igual a dos. El proceso de desorción fue posible, utilizando hidróxido de sodio $\mathrm{NaOH}$ como solución extractora. La capacidad de adsorción de semillas fue de 10.2 y $20.2 \mathrm{mg} \mathrm{g}^{-1}$ para biomasa in natura y tratada con $\mathrm{HCl}$.
\end{abstract}

Palabras clave: Adsorción; Adsorbente alternative; Azul nylosan N-BLN; Tintes.

\title{
1. Introdução
}

São conhecidos cerca de dez mil corantes, sendo que vinte porcento desse total são utilizados nas industrias têxteis. A indústria têxtil é a que mais utiliza corantes, sendo que vinte por cento do total utilizado é descartado na forma de efluente, causando possíveis problemas ambientais (Guaratini, \& Zanoni, 2000; Dallago, Smaniotto, \& Oliveira, 2005). Dessa forma os impactos ambientais causados por efluentes industriais tem sido agravados nos últimos anos, e chama atenção de todos os seguimentos da sociedade (Pinto et al, 2016; Bharathi \& Ramesh, 2013).

Os corantes têxteis são em sua grande maioria, sintéticos e possuem estrutura química complexa, o que torna a degradação dessas espécies químicas desafiadora, uma vez que são, em sua maior parte, não-biodegradáveis e estáveis a luz e calor (Monteiro et al., 2017).

Dentre as técnicas disponíveis para o tratamento de efluentes, a técnica de adsorção se desta, pelo seu baixo custo, simplicidade e eficiência (Santos et al., 2008; Asouhidou, Triantafyllidis, Lazaridis, \& Matis, 2009).

A adsorção em coluna de leito fixo apresenta grandes vantagens, frente a adsorção em batelada, temos como vantagens: o pequeno espaço, a simples operação, a possibilidade de tratamento de grandes volumes de efluentes de forma contínua podendo variar a concentração na alimentação da coluna. A ampliação da escala de bancada, para uma industrial é fácil, por esses motivos esse método é o mais empregado entre os sistemas contínuos (Costa, 1998; Valdman, Erijman, Pessoa, \& Leite, 2001). Outra facilidade que colunas de leito fixo trazem é que no momento em que o adsorvente for saturado (alcançar a capacidade máxima de adsorção), ele pode ser substituído ou regenerado. A medida que o adsorvato é percolado, o adsorvente vai retendo-o, logo a concentração do adsorvato aumenta dentro da coluna até que aconteça a saturação, onde a concentração do efluente e do afluente é igual (Garpar, 2003).

As curvas de ruptura ou curvas de trespasses são curvas construídas pela concentração de efluente por afluente versus o tempo ou volume de fluído tratado. A Figura 1 traz um exemplo dessa curva. 
Figura 1. Curva de Trespasse ou Curva de Ruptura (momento onde ocorre a saturação do adsorvente).

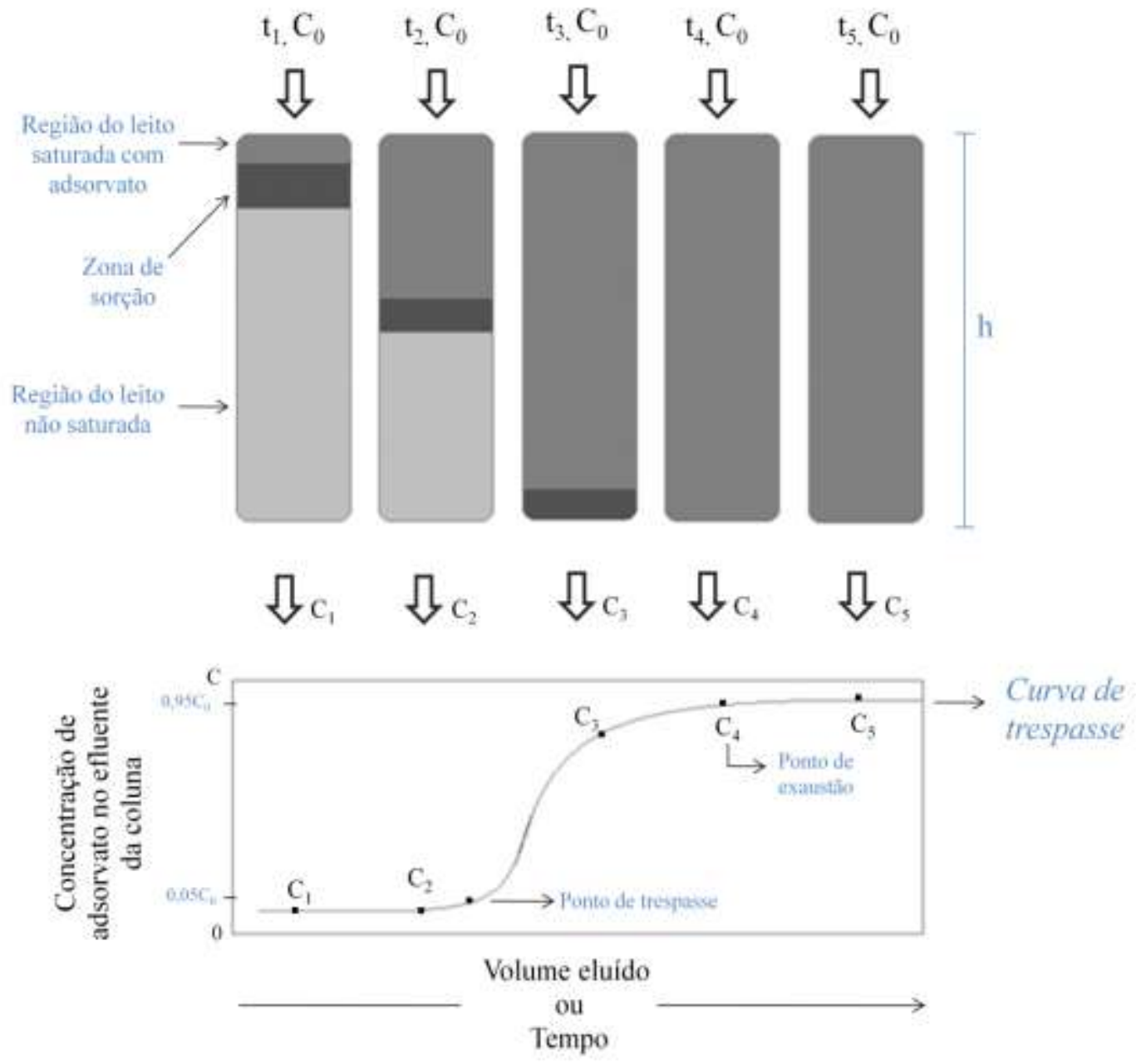

Fonte: Guimarães (2010).

No "ponto de trespasse" o adsorvato começa a eluir da coluna, isso acontece pois os sítios ativos do adsorvente vão sendo ocupados, e dessa forma a concentração do adsorvato no efluente vai aumentando até o ponto onde a concentração de saída é igual a concentração de entrada, esse momento é evidenciado no gráfico pelo "ponto de exaustão", a partir desse ponto o adsorvente atingiu a sua saturação, sendo necessário a regeneração ou troca do adsorvente (Reynolds, \& Richards, 1995; McCabe, Smith, \& Harriott, 1993).

A indústria têxtil é um setor em constante expansão e grande consumidora de água e produtos químicos, portanto gera diariamente grandes quantidades de efluentes líquidos (Monteiro et al., 2017), com isso o tratamento desses resíduos se fazem necessário.

O adsorvente mais utilizado é o carvão ativado, apresentando um auto custo, por isso cada vez mais o uso de adsorventes alternativos estão sendo utilizados, Montanher, de Farias, \& Dalpasquale (2019) utilizou serragem de mdf para a adsorção de corantes têxteis, obtendo sucesso no tratamento, Hameed, Muthirulan, \& Sundaram (2017) utilizaram a semente de varias plantas para testar a adsorção de corantes, Smitha et al. (2017) utilizaram o cucumis sativus, e Kushwaha, Gupta, \& Chattopadhyaya (2014) que utilizou resíduos da planta Daucus carota. Os autores não tem conhecimento de trabalhos que utilizaram resíduos de sementes de maracujá para avaliar a adsorção do corante Nylosan Azul N-BLN.

Portanto o objetivo desse trabalho foi de avaliar foi avaliar o resíduo do maracujá como adsorvente alternativo do 
corante têxtil Nylosan azul N-BLN, testar o efeito da força iônica e do pH da solução na eficiência de adsorção e realizar o processo de dessorção.

\section{Metodologia}

\subsection{Amostra}

O design selecionado para o presente estudo foi laboratorial e cientifico (Pereira, Shitsuka, Pereira, \& Shitsuka, 2018). Preparou-se uma solução estoque de $1 \mathrm{~g} \mathrm{~L}^{-1}$ do corante Nylosan azul N-BLN. Para a determinação do comprimento de onda máxima de absorção, obtiveram-se espectros de absorção na região do visível. Para a obtenção dos espectros utilizou-se cubetas de poliestireno com $1 \mathrm{~cm}$ de caminho óptico e espectrofotômetro UV-VIS da Perkin Elmer, e realizou-se uma varredura entre 400 e $720 \mathrm{~nm}$, encontrando-se dessa forma os valores de $\lambda_{\text {máx }}$ para o corante.

\subsection{Obtenção dos resíduos de Maracujá}

As frutas de maracujá (Passiflora edulis) foram obtidas em mercados e frutarias da cidade de Apucarana, Paraná, Brasil. Inicialmente separou-se as cascas da polpa, após triturou-se a polpa, e dessa forma separou a polpa das sementes, retirou do liquidificador e reservou-o.

Posteriormente lavaram-se os resíduos das sementes, em água corrente, em seguida os mesmos foram secos em estufa com circulação de ar à $80^{\circ} \mathrm{C}$ por 12 horas. Logo após os resíduos foram triturados novamente e peneirados em peneira de 425 $\mu \mathrm{m}$, para assim obter uma granulometria mais uniforme. Dessa forma obtivemos os resíduos de sementes.

\subsection{Tratamentos dos resíduos de maracujá}

Os resíduos de maracujá passaram por um tratamento químico. Realizou-se os tratamentos químicos com ácido clorídrico (HCl) na concentração de $0,10 \mathrm{~mol} \mathrm{~L}^{-1}$. Para a execução desse tratamento, em béqueres de $250 \mathrm{~mL}$ misturou-se $20 \mathrm{~g}$ da biomassa com $150 \mathrm{~mL}$ da solução ácida. Agitou-se a mistura por 1 hora à temperatura ambiente em agitador magnético. Em seguida os resíduos foram lavados com água destilada e secados em estufa com circulação de ar à $80^{\circ} \mathrm{C}$ durante 6 horas.

Dessa forma, os estudos de adsorção foram realizados com os resíduos in natura, tratado com $\mathrm{HCl}$.

\subsection{Estudos de adsorção}

Realizaram-se os ensaios de adsorção em sistema de coluna de leito fixo utilizando uma coluna cromatográfica com torneira de vidro de $15 \times 200 \mathrm{~mm}$. Foram utilizadas $0,8 \mathrm{~g}$ de sementes de maracujá ambas secas. Os resíduos de maracujá foram hidratados com água destilada por 30 minutos, em seguida o resíduo hidratado foi percolado até a completa acomodação do leito, logo após pérolas de vidro foram inseridas na coluna para evitar deslocamento do adsorvente durante os ensaios.

Após a montagem da coluna a solução do corante foi percolada com concentração inicial de $75 \mathrm{mg} \mathrm{L}^{-1}$ para o corante Nylosan azul N-BLN (aniônico/ácido). Coletou-se o efluente da coluna em alíquotas de $25 \mathrm{~mL}$ usando provetas até a saturação do adsorvente. Determinou-se a concentração do corante nas alíquotas utilizando o espectrofotômetro UV-VIS da Perkin Elmer por meio de curvas de calibração.

\subsubsection{Efeito da força iônica}

Para esse estudo preparou-se solução do corante usando como eletrólito o $\mathrm{NaCl}$ em duas concentrações: 0,10 e 1,0 mol L ${ }^{-1}$. Em seguida os estudos de adsorção foram conduzidos como descrito anteriormente. 


\subsubsection{Efeito do $\mathrm{pH}$}

Para esse estudo a solução do corante foi preparada em pH 2, pH 12 (ajustados com $\mathrm{HCl}$ ou $\mathrm{NaOH} \mathrm{0,10} \mathrm{mol} \mathrm{L-1)} \mathrm{e} \mathrm{no}$ pH natural da solução aquosa do corante. Em seguida os estudos de adsorção foram conduzidos como descrito anteriormente.

\subsubsection{Obtenção das curvas de saturação e dessorção}

Para a obtenção das curvas de saturação percolou-se as soluções dos corantes até a total saturação do adsorvente. Curvas de volume percolado $(\mathrm{mL})$ por $\mathrm{C}_{\mathrm{v}} / \mathrm{C}_{\mathrm{i}}$ foram traçadas. Onde $\mathrm{C}_{\mathrm{v}}$ é a concentração do corante na alíquota percolada e $\mathrm{C}_{\mathrm{i}}$ concentração inicial do corante $\left(75 \mathrm{mg} \mathrm{L}^{-1}\right)$. Após a saturação, que foi constatada quando a coloração de entrada na coluna era igual a coloração de saída, as colunas foram percoladas com solução de $\mathrm{NaOH} 0,10 \mathrm{~mol} \mathrm{~L}^{-1}$ para a dessorção do corante. Recolheu-se alíquotas de $25 \mathrm{~mL}$ dos corantes. As curvas de dessorção foram obtidas plotando-se o volume percolado da solução extratora pela concentração de corante extraído $\left(\mathrm{mg} \mathrm{L}^{-1}\right)$.

\subsubsection{Cálculo da capacidade máxima de adsorção}

A capacidade máxima de adsorção do adsorvente presente em uma coluna, q $\left(\mathrm{mg} \mathrm{g}^{-1}\right)$, expressa a quantidade de adsorvato que pode ser adsorvido por grama de adsorvente e pode ser determinada pela Equação 1 (Geankopolis, 1993).

$$
q=\frac{C_{i} \cdot Q}{m} \int_{0}^{t}\left(1-\frac{C v}{C i}\right) d t
$$

Onde:

$\mathrm{q}$ = capacidade máxima de adsorção $\left(\mathrm{mg} \mathrm{g}^{-1}\right)$;

$\mathrm{C}_{\mathrm{i}}=$ concentração inicial do adsorvato $\left(\mathrm{mg} \mathrm{L}^{-1}\right)$;

$\mathrm{C}_{\mathrm{v}}=$ concentração do fluido na saída da coluna $\left(\mathrm{mg} \mathrm{L}^{-1}\right)$;

$\mathrm{Q}=$ vazão volumétrica da solução $\left(\mathrm{L} \mathrm{min}^{-1}\right)$;

$\mathrm{t}=$ tempo $(\min )$;

$\mathrm{m}=$ massa seca do adsorvente $(\mathrm{g})$.

Para a determinação de " $\mathrm{q}$ " utilizou-se o software Origin 8.0. Um gráfico de tempo $(\min )$ versus $\left(1-\mathrm{C}_{\mathrm{v}} / \mathrm{C}_{\mathrm{i}}\right)$ foi plotado e a área sobre o gráfico determinada. Essa área foi então multiplicada pelo fator $\mathrm{C}_{\mathrm{i}} \cdot \mathrm{Q} / \mathrm{m}$.

\section{Resultados e Discussão}

Para que a quantificação do corante Nylosan azul N-BLN fosse possível de ser determinada, primeiramente o valor de $\lambda_{\text {máx }}$ deve ser encontrado, para isso realizou-se uma varredura para encontrar os seguintes espectros de absorção na região do visível (Figura 2). 
Figura 2. Espectros de Absorção na região do visível. Em preto temos o corante Nylosan Azul N-BLN.

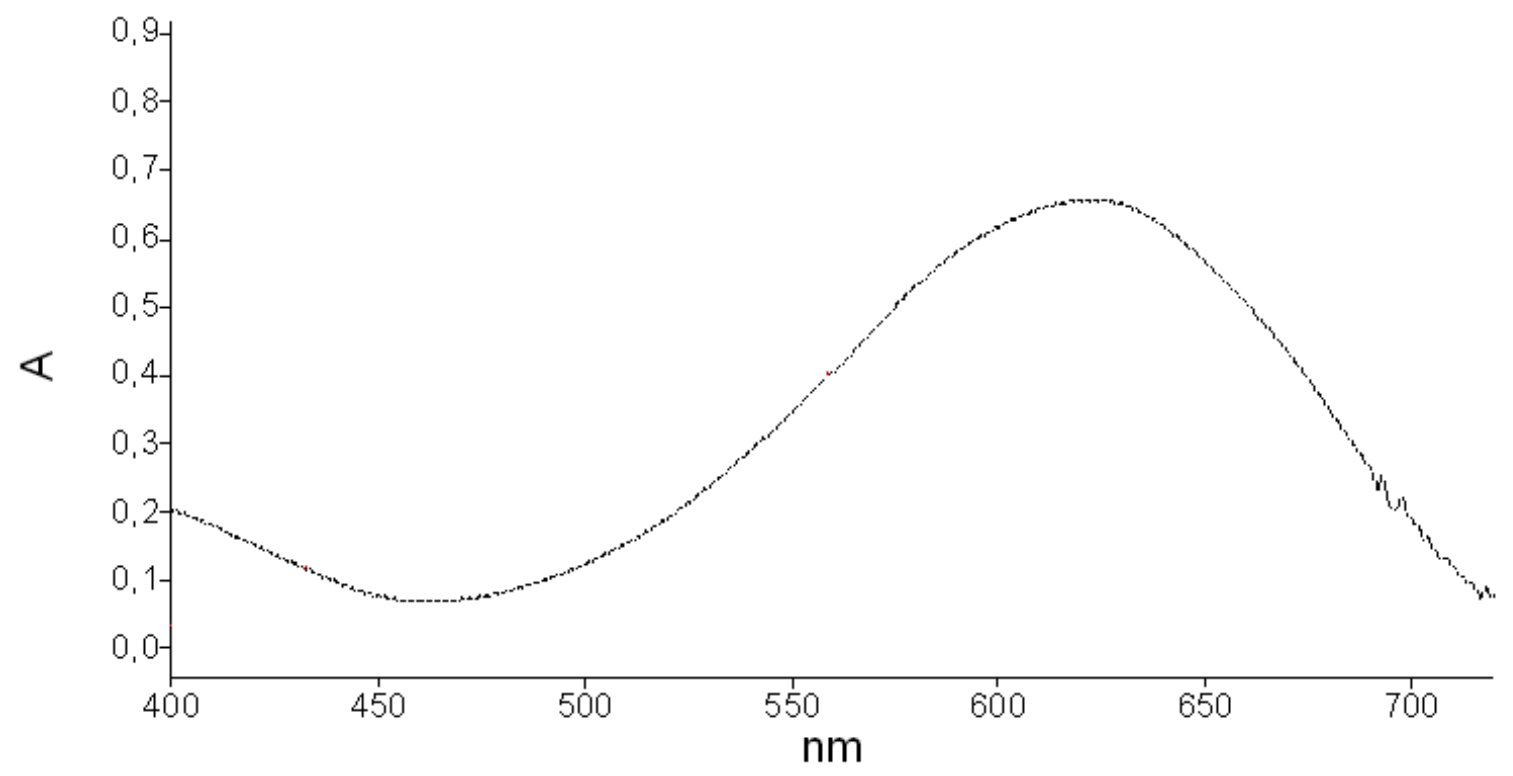

Fonte: Autores (2021).

Utilizando o espectro de absorção foi possível encontrar o valor de $\lambda_{\operatorname{máx}}$ que para o corante Nylosan Azul N-BLN é igual a $620 \mathrm{~nm}$, com o valor de $\lambda_{\text {máx }}$ foi possível construir curva de calibração (Figura 3), essa curva foi utilizada para determinação da concentração de corante que era recolhido após passagem pela coluna.

Figura 3. Curvas de Calibração para determinação da concentração do corante Nylosan azul N-BLN.

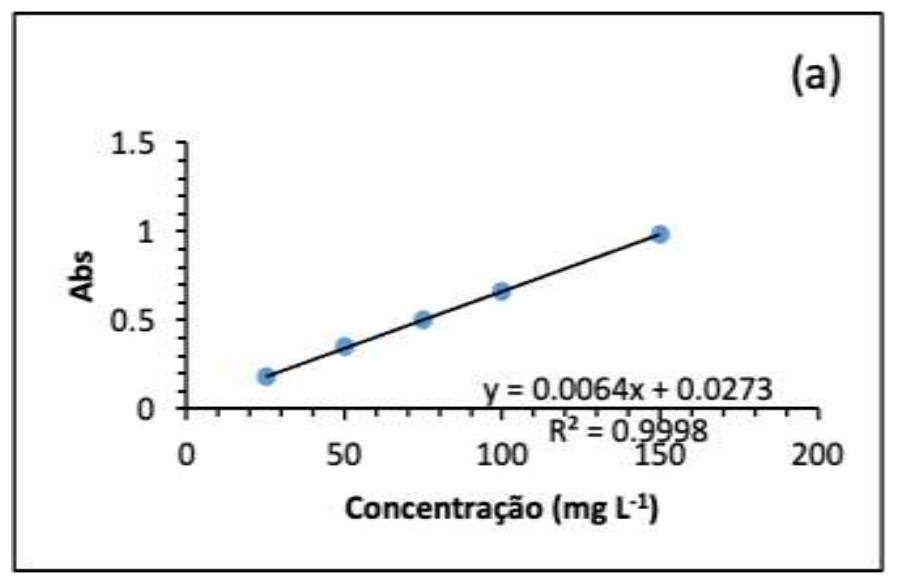

Fonte: Autores (2021).

Para a curva foi obtida a equação da reta, para posteriormente utilizar-se nos cálculos de concentração, e também se obteve o coeficiente de correlação $\left(\mathrm{R}^{2}\right)$, esse valor é muito próximo de 1 , isso significa que existe uma boa correlação entre a variável na faixa de concentração estudada.

Após a curva de calibração ser obtida, iniciou-se o estudo de adsorção. O primeiro passo do trabalho foi a otimização da montagem da coluna, e otimização da massa a ser utilizada. Diversas massas foram testadas, em massas maiores a vazão da coluna era demasiadamente lenta, acarretando com isso a impossibilidade de sua aplicação. Foram testadas colunas com placa porosa, e colunas com algodão, no lugar da placa porosa, foi possível observar que quando utilizava-se a coluna com placa porosa, o processo de adsorção também se tornava lento, por isso foi escolhido coluna com algodão para realizar o 
empacotamento da coluna. Dessa forma as massas dos adsorventes e forma de preenchimento da coluna otimizados estão descritos no item 2.4 desse trabalho.

\subsection{Estudos de adsorção}

O corante Nylosan azul N-BNL é um corante aniônico, utilizado na indústria têxtil, por isso realizou-se o tratamento ácido dos resíduos de maracujá para a adsorção desse corante. O objetivo desse tratamento era o de tornar a superfície das partículas de resíduos de maracujá positivas e portanto, com afinidade por corantes aniônicos. A Figura 4 apresenta as curvas de saturação do corante azul em sementes de maracujá in natura e tratada com $\mathrm{HCl}$.

Figura 4. Curvas de saturação para a adsorção do corante Nylosan azul N-BNL em sementes de maracujá in natura e tratada $\operatorname{com~} \mathrm{HCl}\left(\mathrm{C}_{\mathrm{i}}=75 \mathrm{mg} \mathrm{L}^{-1}\right.$ e $\left.\mathrm{m}=0,8 \mathrm{~g}\right)$.

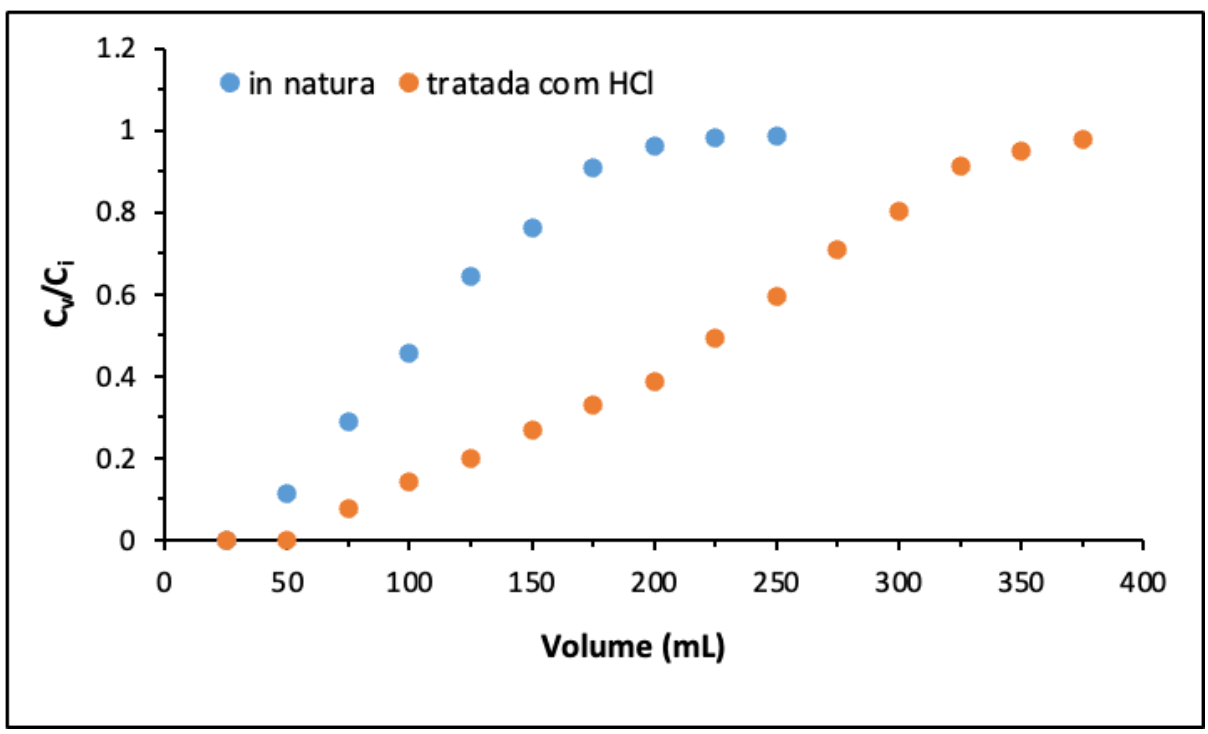

Fonte: Autores (2021).

Quando analisamos uma curva de saturação, existem dois pontos importantes, o primeiro é o ponto de ruptura, é a partir desse ponto que começa a aparecer coloração no efluente da coluna, ou seja, é o momento em que $\mathrm{C}_{\mathrm{v}} / \mathrm{C}_{\mathrm{i}}$ deixa de ser zero. O outro ponto a ser analisado é o ponto de saturação da coluna, esse ponto é observado quando o valor de $\mathrm{C}_{\mathrm{v}} / \mathrm{C}_{\mathrm{i}}$ é igual a um. Dessa forma, a Figura 4 mostra que o tratamento com $\mathrm{HCl}$ favoreceu a adsorção do corante azul por sementes de maracujá, pois ambos os pontos de ruptura e saturação aconteceram em volumes maiores do que a semente in natura.

Tabela 1 - Capacidade máxima de adsorção do corante Nylosan azul N-BNL em resíduo de Maracujá usando sistema de coluna de leito fixo.

\begin{tabular}{c|c}
\hline Resíduo de Maracujá & $\mathbf{q}\left(\mathbf{m g} \mathbf{~ g}^{-\mathbf{1}}\right)$ \\
\hline Semente in natura & 10,3 \\
Semente tratada com $\mathrm{HCl}$ & 20,2 \\
\hline
\end{tabular}

Fonte: Autores (2021).

Com os valores de q, observamos que as sementes tratadas com $\mathrm{HCl}$ tem uma capacidade de adsorção maior que as sementes in natura e que o tratamento químico aumenta a capacidade de adsorção do corante azul (aniônico). 
Montanher, de Farias, \& Dalpasquale (2019) usando serragem de MDF in natura como adsorvente do corante Nylosan azul N-BNL em sistema de coluna de leito fixo obteve um valor inferior de $\mathrm{q}=6,3 \mathrm{mg}^{-1}$, evidenciado que as sementes de maracujá apresenta uma capacidade de adsorção maior, logo é um bom adsorvente.

Um parâmetro importante no processo de adsorção é a força iônica da solução de adsorvato. Íons dissolvidos, proveniente dos sais, podem ajudar no processo de adsorção ou prejudicar dependendo da carga e do tamanho da molécula.

A Figura 5 mostra o efeito da força iônica na adsorção do corante azul em resíduos de maracujá. As curvas de saturação foram construídas com o corante em água e em duas solução aquosas de $\mathrm{NaCl}$.

Figura 5. Efeito da Força iônica na adsorção do corante Nylosan azul N-BNL em sementes de maracujá in natura $\left(\mathrm{C}_{\mathrm{i}}=75 \mathrm{mg}\right.$ $\mathrm{L}^{-1}$ e $\left.\mathrm{m}=0,8 \mathrm{~g}\right)$.

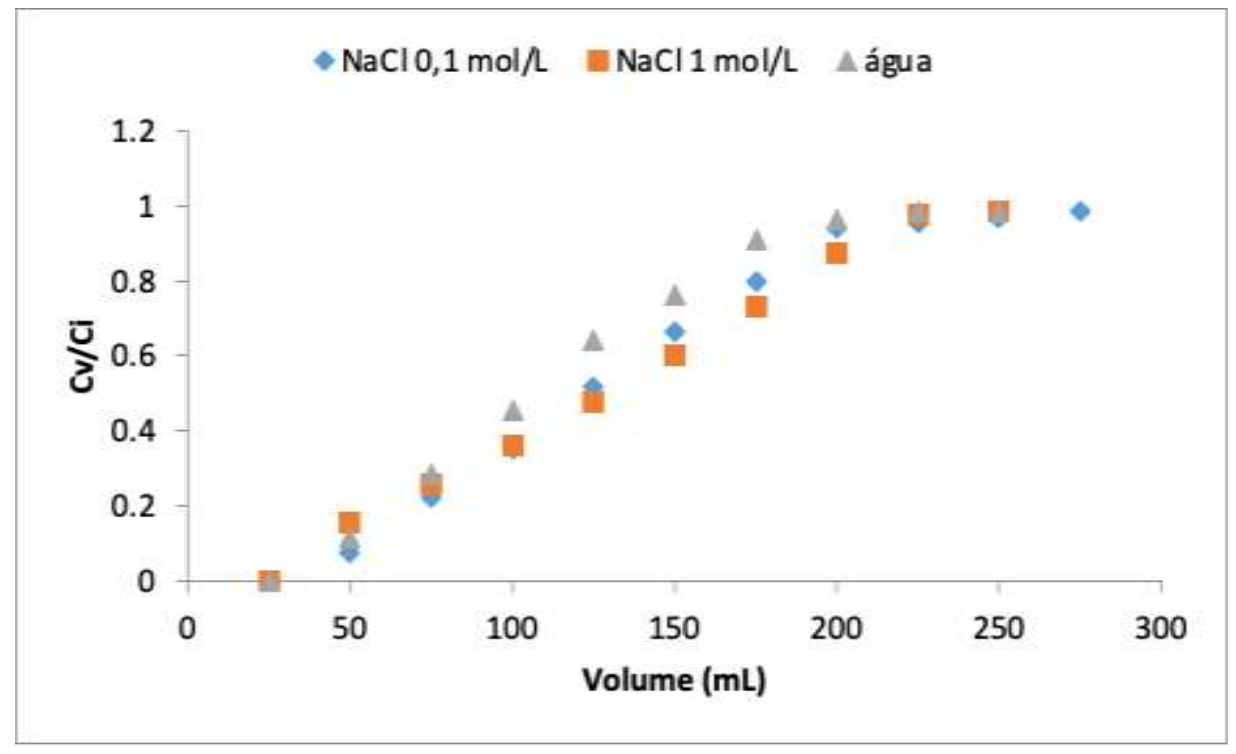

Fonte: Autores (2021).

Observa-se que a força iônica interfere muito pouco na eficiência de adsorção do corante azul pelos resíduos de maracujá. O teste de adsorção avaliando o fator da força iônica foi realizado, pois é muito comum na indústria têxtil fazer banhos de sais para aumentar a fixação do corante nas fibras, como a adsorção do corante azul não teve muito comprometimento com a elevação da força iônica, logo seria possível utilizar os resíduos de maracujá para fazer o tratamento desses efluentes (Salem, 2008)

$\mathrm{O}$ pH da solução contendo o adsorvato é um fator muito importante em processos de adsorção, pois pode causar protonação e desprotonação de sítios ativos tanto no adsorvato quanto no adsorvente.

O corante Nylosan azul N-BNL faz parte do grupo dos corantes ácidos/aniônicos, pois possui em sua estrutura o grupo sulfônico desprotonado. A solução aquosa $75 \mathrm{mg} \mathrm{L}^{-1}$ do corante azul apresentou pH 8,4, provavelmente devido a hidrólise desse grupo funcional:

$$
\mathrm{R}-\mathrm{SO}_{3^{-}(\mathrm{qq})}^{-}+\mathrm{H}_{2} \mathrm{O}_{(\mathrm{l})} \rightleftarrows \mathrm{R}-\mathrm{SO}_{3} \mathrm{H}_{(\mathrm{aq})}+\mathrm{OH}_{(\mathrm{aq})}^{-}
$$

A Figura 6 apresenta o efeito do pH na adsorção corante azul nos resíduos de Maracujá. 
Figura 6. Efeito do pH na adsorção do corante Nylosan azul N-BNL em sementes de maracujá in natura $\left(\mathrm{C}_{\mathrm{i}}=75 \mathrm{mg} \mathrm{L}^{-1}\right.$ e $\mathrm{m}=$ $0,8 \mathrm{~g})$.

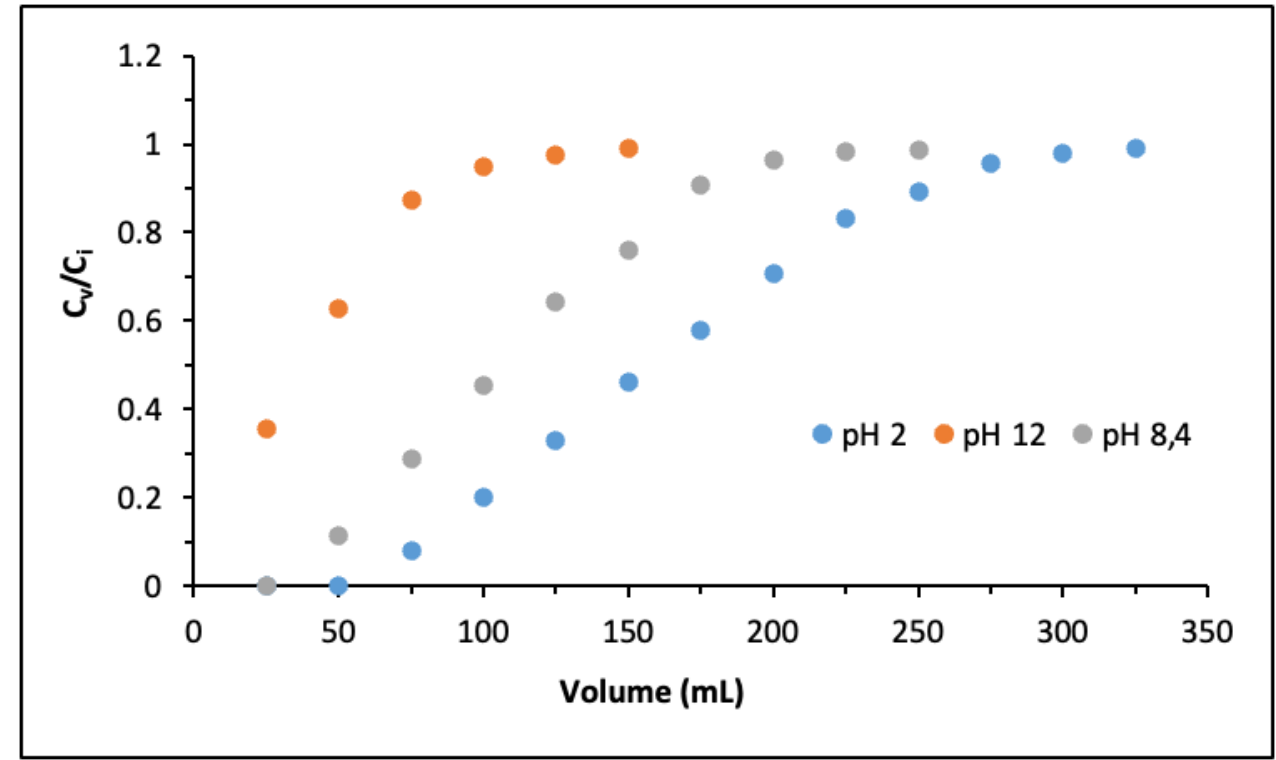

Fonte: Autores (2021).

Para o adsorvente o pH 12 foi muito pouco eficiente, já o pH 2 aumentou bastante a eficiência. Montanher, de Farias, \& Dalpasquale (2019) fez a mesma observação ao estudar a adsorção do corante azul em serragem de MDF.

$\mathrm{O}$ pH ácido ajuda na adsorção de adsorvatos aniônicos devido a protonação de sítios ativos do adsorvato (Monteiro et al., 2017).

Pensando em um possível reaproveitamento do corante e dos adsorventes realizou-se a dessorção do corante azul usando como solução extratora o $\mathrm{NaOH} 0,1 \mathrm{~mol} \mathrm{~L}^{-1}$, pensando em um processo de troca iônica. A dessorção é o inverso da adsorção que ocorre com o equilíbrio de protonação ácido-base (Souza et al., 2020). A Figura 7 mostra a curva de dessorção do corante azul em semente de maracujá.

Figura 7. Curva de dessorção do corante Nylosan Azul N-BNL retido em sementes de maracujá in natura e tratada com HCl.

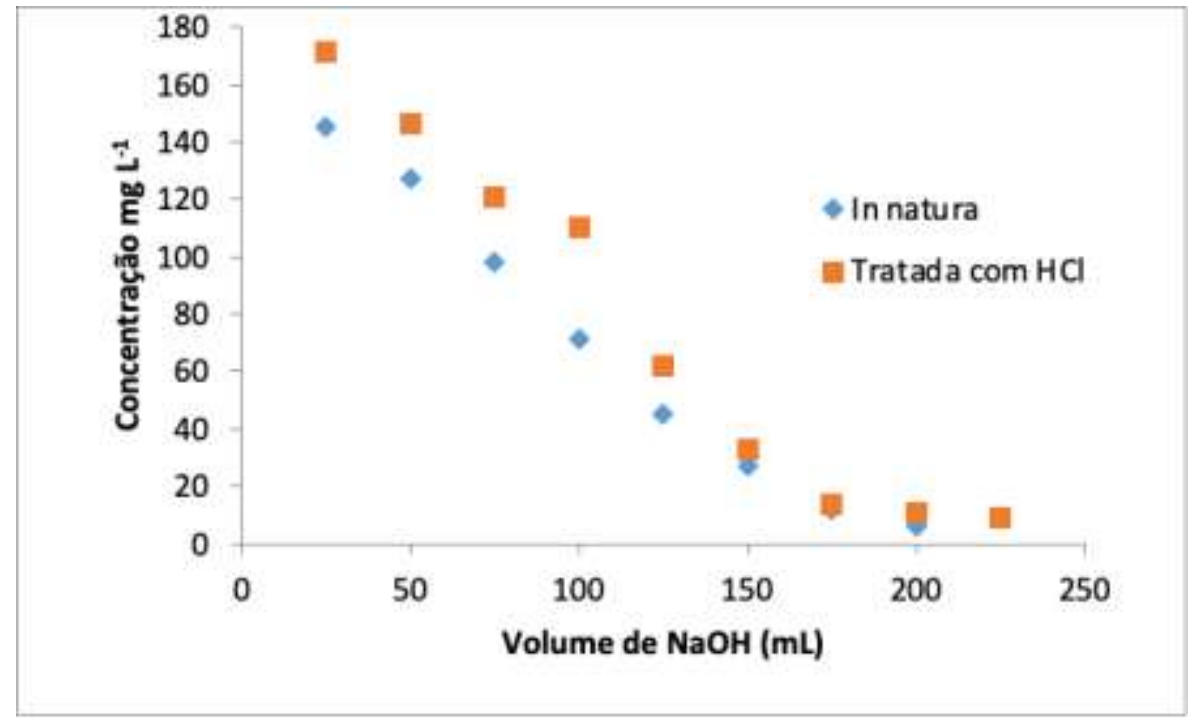

Fonte: Autores (2021). 
É possível observar que processo de dessorção acontece, ou seja, é possível recuperar o corante que havia sido retido na coluna. Nota-se a partir de $25 \mathrm{~mL}$ de hidróxido de sódio $(\mathrm{NaOH})$, já é retirado uma boa quantidade de corante da coluna, e após os $200 \mathrm{~mL}$ quase todo o corante é recuperado.

\section{Conclusão}

A partir dos estudos de adsorção analisados foi possível concluir que o corante azul nas sementes, in natura tem interação menor que quando tratadas com $\mathrm{HCl}$, que aumentou assim a eficiência de adsorção. $\mathrm{O}$ tratamento químico aumentou mais a capacidade de adsorção das sementes, o aumento foi significativo acima dos $20 \%$.

Testando a força iônica pôde verificar que houve pouca influência na capacidade de adsorção. Nos ensaios testando o efeito do $\mathrm{pH}$ foi possível observar que esse parâmetro influencia diretamente, e que quanto maior o valor de $\mathrm{pH}$ da solução menor a eficiência de adsorção, portanto em $\mathrm{pH}$ menor o processo de adsorção foi favorecido. $\mathrm{O}$ parâmetro de $\mathrm{pH}$ apresentou extrema importância, pois afetou diretamente o processo de adsorção. O processo de dessorção foi possível para o corante retido nos resíduos de maracujá in natura e tratados com e $\mathrm{HCl}$, sendo possível o corante e a biomassa serem reutilizados novamente.

Dessa forma foi possível concluir que a biomassa de semente pode ser utilizadas numa escala industrial, pois o resíduo é barato, de fácil obtenção. Com isso trabalhos futuros devem ser desenvolvidos para avaliar outras biomassas para o tratamento desse mesmo corante, e também para outros corantes, afim de tornar o processo de adsorção mais eficaz e barato.

\section{Agradecimentos}

Os autores agradecem a Universidade Tecnológica Federal do Paraná - Campus Apucarana, Conselho Nacional de Desenvolvimento Científico e Tecnológico (CNPq) e Coordenação de Aperfeiçoamento de Pessoal de Nível Superior (CAPES) pelo auxílio financeiro.

\section{Referências}

Asouhidou, D. D., Triantafyllidis, K. S., Lazaridis, N. K., \& Matis, K. A. (2009). Adsorption of Remazol Red 3BS from aqueous solutions using APTES-and cyclodextrin-modified HMS-type mesoporous silicas. Colloids and Surfaces A: Physicochemical and Engineering Aspects, 346), 83-90.

Bharathi, K. S., \& Ramesh, S. T. (2013). Removal of dyes using agricultural waste as low-cost adsorbents: a review. Applied Water Science, 3, 773-790.

Costa, C. A. (1998). Sorção de íons cobre, níquel e zinco com o rejeito do beneficiamento de carvões e outros materiais alternativos. Universidade Federal do Rio Grande do Sul, Porto Alegre-RS.

Dallago, R. M., Smaniotto, A., \& Oliveira, L. C. A. D. (2005). Resíduos sólidos de curtumes como adsorventes para a remoção de corantes em meio aquoso. Química Nova, 28, 433-437.

Gaspar, A. T. F. D. S. (2003). Bioadsorção de cromo em algas marinhas utilizando coluna extratora.

Geankopolis, C. J. (1993). Transport processes and unit operations. Prentice-Hall.

Guaratini, C. C., \& Zanoni, M. V. B. (2000). Corantes têxteis. Química nova, 23, 71-78.

Guimarães, D. (2010). Tratamento de efluentes ricos em sulfato por adsorção em resinas de troca iônica.

Hameed, K. S., Muthirulan, P., \& Sundaram, M. M. (2017). Adsorption of chromotrope dye onto activated carbons obtained from the seeds of various plants: equilibrium and kinetics studies. Arabian Journal of Chemistry, 10, S2225-S2233.

Kushwaha, A. K., Gupta, N., \& Chattopadhyaya, M. C. (2014). Removal of cationic methylene blue and malachite green dyes from aqueous solution by waste materials of Daucus carota. Journal of Saudi Chemical Society, 18, 200-207.

McCabe, W. L., Smith, J. C., \& Harriott, P. (1993). Unit operations of chemical engineering, 5, 154.

Montanher, S. F., de Farias, L. B. N., \& Dalpasquale, M. (2019). Adsorção de corantes têxteis em serragem de MDF (Medium-Density Fiberboard). Brazilian Journal of Development, 5), 14776-14789. 
Research, Society and Development, v. 10, n. 13, e573101321594, 2021

(CC BY 4.0) | ISSN 2525-3409 | DOI: http://dx.doi.org/10.33448/rsd-v10i13.21594

Monteiro, M. S., de Farias, R. F., Chaves, J. A. P., Santana, S. A., Silva, H. A., \& Bezerra, C. W. (2017). Wood (Bagassa guianensis Aubl) and green coconut mesocarp (cocos nucifera) residues as textile dye removers (Remazol Red and Remazol Brilliant Violet). Journal of environmental management, 204, 23-30.

Pereira, A. S., Shitsuka, D. M., Pereira, F. J., \& Shitsuka, R. (2018). Metodologia da pesquisa científica. [eBook]. Santa Maria. Ed. UAB / NTE / UFSM. https://repositorio.ufsm.br/bitstream/handle/1/15824/Lic_Computacao_Metodologia-Pesquisa-Cientifica.pdf?sequence=1 .

Pinto, TF, Bezerra, CW, Silva, DS, SILVA, EC, Vieira, AP, Airoldi, C., ... \& Santana, SA (2016). Derivado da serragem para aplicação ambiental: química, funcionalização e remoção de corante têxtil em solução aquosa. Anais da Academia Brasileira de Ciências, 88, 1212-1220.

Reynolds, T. D., \& Richards, P. A. C. (1995). Unit operations and processes in environmental engineering (No. 628.162 R333u Ej. 1). PWS Publishing Company,

Salem, V. (2010). Tingimento têxtil: fibras, conceitos e tecnologias. Editora Blucher.

Santos, D. O., Santana, S. A., Bezerra, C. W., Oliveira Filho, J. R., Silva, H. A., \& Mouchrek Filho, V. E. (2008). Remoção de corantes têxteis por mesocarpo de coco verde. Mens Agitat, (3), 9-16.

Smitha, T., Santhi, T., Prasad, A. L., \& Manonmani, S. (2017). Cucumis sativus used as adsorbent for the removal of dyes from aqueous solution. Arabian Journal of Chemistry, 10, S244-S251.

Souza, J. L., Holanda, C. A., de Lima Aires, A. M., dos Reis Almeida, T., de Sousa Oliveira, E., da Costa Rocha, M. B., \& Costa, A. N. (2020). Potencialidades da Eichhornia azurea (aguapé) na remoção do corante têxtil turquesa remazol em meio aquoso: Estudo dos mecanismos cinéticos de adsorção. Brazilian Journal of Development, 6(10), 76037-76053.

Valdman, E., Erijman, L., Pessoa, FLP, \& Leite, SGF (2001). Biossorção contínua de Cu e Zn pela biomassa residual imobilizada Sargassum sp. Process Biochemistry , 36 (8-9), 869-873. 